\title{
The impact of Corona pandemic on consumer's food consumption
}

\author{
Vulnerability of households with children and income losses and change in sustainable \\ consumption behavior
}

\author{
Adriano Profeta ${ }^{1}$ (1) - Shahida Anusha Siddiqui ${ }^{1} \cdot$ Sergiy Smetana ${ }^{1}$. Sayed Mahdi Hossaini ${ }^{1} \cdot$ Volker Heinz $^{1}$. \\ Christian Kircher ${ }^{1}$
}

Received: 16 March 2021 / Revised: 20 July 2021 / Accepted: 29 July 2021 / Published online: 16 August 2021

(C) The Author(s) 2021

\begin{abstract}
The ongoing corona crisis affected many people worldwide by restrictions in their everyday lives. The question arises to what extent the pandemic has accelerated diet trends or general differences in food consumption between different population groups. For this purpose, an online-survey was carried out in order to determine the effects of the corona lockdown on food consumption, shopping behaviour and eating habits in Germany. The aspects of sustainability and health were given special consideration in this study, reflecting people choices of healthier and more environmentally conscious foods. This study demonstrates that the corona pandemic has a significant impact on consumers' eating habits. More food was eaten, and more convenience products such as ready-made meals and canned food with a longer shelf life were purchased. The consumption of alcohol and sweets has also increased. In return, there was a reduced consumption of fresh fruits and vegetables. The findings reveal that families who are financially affected by the pandemic represent a vulnerable group. With the ongoing pandemic, possible lockdowns, corona-related closings of schools and kindergartens, severe health consequences are expected long term, especially for this population group.
\end{abstract}

Keywords Covid-19 $\cdot$ Corona $\cdot$ Consumer behaviour $\cdot$ Food $\cdot$ Health

\section{Introduction}

The ongoing corona pandemic affects many people worldwide by restrictions in their everyday lives. It is to highlight that the pandemic has also influenced the eating behaviour and shopping habits of consumers (Scarpa and Rose 2008). Due to possible quarantine phases, consumers were concerned about which type of food and its quantities should be stored (Dammeyer 2020). In addition, there were short-term out-of-stock situations in the food retail sector (Liu et al. 2020) for selected products (e.g. flour, pasta, disinfectants, etc.).

In this context, the Lower Saxony State Food Industry Association-LI Food ${ }^{1}$ carried out a representative online

Adriano Profeta

a.profeta@dil-ev.de

1 DIL e.V.-German Institute of Food Technologies, Prof.-von-Klitzing-Straße 7, 49610 Quakenbrück, Germany survey with 973 participants in April 2020, during the first lockdown in Germany. The survey aimed to determine the effects of the corona pandemic on food consumption, shopping behaviour and eating habits in Germany. The aspects of sustainability and health were given special consideration in the study, reflecting people choices of healthier and more environmentally conscious foods. Moreover, the survey reflected whether there were changes in the consumption quantity in different product categories or food waste avoidance. Changes in purchases of organic and locally produced products due to corona effects were also considered. The focus was primarily on households with children and households affected by a loss of income due to the lockdown. In general, the question arises to what extent the pandemic has accelerated diet trends or general differences in food consumption between different population groups. The next section briefly describes existing studies on the subject before presenting the methodology and the study results.

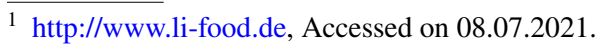




\subsection{Psychological and physical effects of the pandemic and possible effects on the eating and purchasing behaviour of consumers}

\subsection{1 "More food - an instrument for reducing stress"}

It is to hypothesize that the pandemic has directly impacted people's psyche. Even in regions with a relatively low risk of infection, the population was exposed to massive risk communication and media reporting in 2020, which in itself was a relevant psychological stress factor. Also, a considerable part of the population was affected by short-time work or unemployment or was worried about a possible job loss, which could likewise impact psychological well-being (Monsivais et al. 2015; van Hal 2015). In such situation, eating "more" can be a coping strategy to polarize ones' psychology in order to deal with the pandemic and the stress it causes. Increased consumption of (alcoholic) beverages and food can represent an attempt to feel better under stress temporarily (Conway et al. 1981; Laitinen et al. 2002). For Italy's first lockdown, it was observed that households mainly consumed more processed "comfort foods" such as chocolate, chips and snacks (Bracale and Vaccaro 2020; Scarmozzino and Visioli 2020). The longer the lockdown measures persists, the higher is the probability that a permanent risen consumption leads to a higher prevalence of obesity. The consequences could be a rise in diabetes, coronary diseases and cancer in the population (Swinburn et al. 2019).

\subsubsection{Reduced physical activity as an amplifying factor for negative effects}

During the pandemic, physical and sport activities in the population have declined. Children and parents alike spent more time with computer games and online media (Spitzer 2020). In the current edition of the specialist journal "Nervenheilkunde", an article by the well-known neurologist Spitzer (2020) anecdotally quotes a teacher as follows:

"The students, whom I was able to see again for a few hours, spent the 7 weeks almost without exception playing in front of the computer. On average they were 5-10 kilos heavier [...]".

The fatal consequences of the outlined situation becomes more obvious with the background of a publication in Lancet, that states that a $10 \%$ reduction in physical inactivity could lead to additional 533,000 deaths per year worldwide (Wen and $\mathrm{Wu}$ 2012).

\subsubsection{Fear as a driver for the (increased) purchase of specific product categories}

Another mediator of consumer behaviour is the associated risk with Covid-19 of falling ill or dying. Consumers could reduce their risk of infection by using delivery services or buying more packaged foods that are considered more hygienic (Bracale and Vaccaro 2020). It can also be assumed that foods with a longer shelf life will be bought (and thus fewer fresh products such as fruits and vegetables) to minimize shopping frequency and risk of infection in supermarkets. Monteiro (2009) and Monteiro et al. (2011) argue that more processed foods have a negative impact on consumers' health status. Contrarily, there is the behavioural strategy of buying healthier food to strengthen the immune system (Rodríguez-Pérez et al. 2020). It is conceivable that this could result in an increasing demand for more fruits and vegetables or ecologically and regionally produced food.

Another factor influencing consumer behaviour are concerns about food shortages, leading to certain food stockpiling (Bracale and Vaccaro 2020). The market research institute Innofact (Düsseldorf, Germany) interviewed 1037 consumers from March 24th to 25th, 2020, and found that every third German bought significantly more noodles, ready-made meals, toilet paper, rice, flour, and kitchen rolls. ${ }^{2}$ This behaviour change is confirmed by scanner data from the Federal Statistical Office for calendar weeks 9-16, in which there was a "shopping boom" for the products mentioned. The overview across some recent study results, show a trend towards increased consumption and towards stockpiling.

\subsubsection{Consequences of corona-related income loss or unemployment}

In Germany, the pandemic led to increased unemployment and short-time work due to the pandemic. ${ }^{3}$ Besides, there is evidence that with lower education levels, the proportion of people who went on short-time work, unpaid vacation or unemployment was higher. A job loss is twice as likely for someone with an intermediate level of education than for someone with a high level of education. In addition, it was mainly employees with a higher education who had the opportunity to work from home. As a result, this group was exposed to a significantly lower risk of infection than those in employment with an intermediate or low level of education (Naumann et al. 2020).

\footnotetext{
${ }^{2}$ https://innofact-marktforschung.de/news/innofact-corona-studiewer-hamstert-eigentlich-die-nudeln/, Accessed on 11.08.2021., Accessed on 08.07.2021.

${ }^{3}$ http://www.arbeitsagentur.de, Accessed on 08.07.2021.
} 
Table 1 Sociodemography of the survey sample $(n=973)$

\begin{tabular}{ll}
\hline & $\%$ \\
\hline Gender: female & 42.7 \\
Ages groups (years) & \\
$20-39$ & 31.5 \\
$40-59$ & 38.8 \\
$60+$ & 29.7 \\
Household constellation & \\
With children (0-18 years) & 23.1 \\
With children (0-12 years) & 12.0 \\
Two adults without children & 47.0 \\
Singles & 30.0 \\
School education & \\
Low & 10.5 \\
Middle & 54.1 \\
High & 35.5 \\
Income loss: yes & 26.1 \\
\hline
\end{tabular}

A study from the UK (Hendrickson et al. 2006; Monsivais et al. 2015) showed that losing a job can lead to weight gain over certain time. Furthermore, in low-income households, the (high) price can be an obstacle to buying fruit and vegetables (Cassady et al. 2007). During the financial crisis, spending on groceries were reduced in many western industrialized countries, which can be ascribed to a decline in income (Antentas and Vivas 2014; Vlontzos and Duquenne 2013). Since the corona pandemic also represents an economic crisis, it is to hypothesize that the effects described can also be transferred to the recent situation.

\section{Materials and methods}

A population of 973 consumers was interviewed via an online survey about their eating, buying and cooking behaviour before and during the corona pandemic in the period from April 22th to 27th 2020 (Table 1). The questionnaire and the idea for this research was developed by an international consortia of universities and research institutions under the led of the Danish Technology Institute, and the Copenhagen Business School and can be found as supplementary information. 4

The respondents were recruited via the consumer panel of the agency respondi. ${ }^{5}$ Responsibility for household shopping was used as a screening parameter. Only people responsible for purchasing groceries or who stated to share this task at least to $50 \%$ with other members of the household were allowed to participate. The collected data went through a quality and plausibility check by the German Institute of

\footnotetext{
4 http://www.food-covid-19.org, Accessed on 08.07.2021.

5 http://www.respondi.com, Accessed on 08.07.2021.
}

Table 2 Answer options on the frequency of consumption of various foods

\begin{tabular}{ll}
\hline Coding & Answer categories \\
\hline 1 & $\begin{array}{c}\text { Less then once } \\
\text { every 2 weeks or } \\
\text { never } \\
\text { Between once a } \\
\text { week and once } \\
2\end{array}$ \\
& each 2 weeks \\
3 & Once a week \\
4 & 2-3 times per week \\
5 & 4-6 times per week \\
6 & Daily \\
\hline
\end{tabular}

Food Technology's consumer science research platform. The online questionnaire was sent to the panellists via the DIL Quick Smart-Survey Server. ${ }^{6}$

To measure the change in the total amount of food consumed due to Covid-19, a five-point Likert scale with the categories "much less", "slightly less", "no change", "a little more" and "much more" was applied. To measure the change across different product groups, respondents were asked how often they consumed these foods before and during the Covid-19 pandemic for each analyzed product group. The studied product groups were fruit/vegetables, meat, fish, bread, milk, frozen goods, canned food, ready-made meals, cakes/biscuits, sweets and alcohol. The response options for the consumption frequency ranged from "less than once every two weeks or never" to "daily" (Table 2).

For the analysis for each product category (Fig. 3), the mean value (based on the number coding for the response categories) before the pandemic $\left(\bar{x}_{\text {before Covid-19 }}\right)$ and the mean of the change caused by the pandemic $\left(\bar{x}_{\text {change }}=\bar{x}_{\text {before Covid-19 }}-\bar{x}_{\text {during Covid-19 }}\right)$ were calculated. A two-sided $t$-test was applied to analyze whether the consumption frequency in a product category was significantly changed due to the corona pandemic. The $H_{0}$-hypothesis aimed to check whether the measured change in the consumption quantity was equal to zero $\left(\mu_{\text {change }}=0\right)$. The change in consumption frequency is also shown at an individual level in the result section. The values of the numerical coding for the consumption frequency before and during the pandemic were subtracted from each other at the level of the individual respondent (formula I), so that numbers of a maximum of +5 (change from "daily" to "less than once every two weeks or never") to -5 (change from "Less than once every two weeks or never" to "Daily") were possible results (Fig. 3):

$$
\begin{aligned}
\Delta \text { Eating freq. } .= & \text { Eat. freq } \cdot \text { during Covid-19 } \\
& - \text { Eat. freq. } \cdot \text { before Covid-19. }
\end{aligned}
$$

\footnotetext{
${ }^{6}$ http://www.survey.dil-ev.de, Accessed on 08.07.2021.
} 
Table 3 Sample size of the analyzed household segments

\begin{tabular}{llllll}
\hline & Total sample & $\begin{array}{l}\text { No kids and no } \\
\text { income loss }\end{array}$ & $\begin{array}{l}\text { Kids and no } \\
\text { income loss }\end{array}$ & $\begin{array}{l}\text { No kids and } \\
\text { income loss }\end{array}$ & $\begin{array}{l}\text { Kids and } \\
\text { income } \\
\text { loss }\end{array}$ \\
\hline $\begin{array}{l}\text { Sample size } \\
\text { Ø Household size }\end{array}$ & 973 & 579 & 140 & 169 & 85 \\
Age (years) & 2.29 & 1.82 & 4.04 & 1.79 & 3.61 \\
20-39 & 31.5 & $23.8 \%$ & $46.4 \%$ & $34.9 \%$ & $52.9 \%$ \\
$40-59$ & 38.8 & $33.7 \%$ & $47.1 \%$ & $45.0 \%$ & $47.1 \%$ \\
$60+$ & 29.7 & $42.5 \%$ & $6.4 \%$ & $20.1 \%$ & - \\
Education & & & & & \\
Low & 10.5 & $12.4 \%$ & $5.7 \%$ & $9.5 \%$ & $7.1 \%$ \\
Middle & 54.1 & $53.7 \%$ & $54.3 \%$ & $52.1 \%$ & $60.0 \%$ \\
High & 35.5 & $33.9 \%$ & $40.0 \%$ & $38.5 \%$ & $32.9 \%$ \\
\hline
\end{tabular}

To measure further changes in consumer behaviour due to the corona pandemic, again a 5-pole Likert scale with the answer options "much less", "a little less", "no change", "a little more" and "much more" was used. The $\chi^{2}$-test was used to test the relationship between consumers' fear of not getting food and the question of whether more food would be stored during the pandemic (Hair et al. 2010).

The study is relying on the hypothesis that the pandemic has a stronger impact in certain household segments (see Sect. 3.2). Therefore, four household segments were created for an in-depth analysis (Table 3). The presence of children in the household and the extent to which a corona-related loss of income was affected were used as segmentation variables. Differences in consumer behaviour of the analysed households segments were checked via a row of Fisher's exact tests for $2 \times 2$ tables. For this purpose the 5-pole Likert scale with the answer options "much less", "a little less", "no change", "a little more" and "much more" was condensed into the three categories "less" (sum of "much less" and "little less'), "no change" and "more" (sum of "little more" and "much more").

\section{Results and discussion}

\subsection{Stockpiling and the influence of risk perception}

Almost a third of the respondents $(31.4 \%)$ indicated to stockpile more food compared to the time before the pandemic. Simultaneously, the fear of not getting enough food was increased. Before Covid-19, very few study participants $(3 \%)$ were anxious to this effect. In contrast, this value increased almost to $18 \%$ (sum of the values "often" and "occasionally") at the time of the survey (Table 4). Concerning the influence of fear on not getting enough food and stockpiling, the results show that the bigger the fear, the more the study participants were stockpiling $\left(\chi^{2}=55.164 ; d f=2, p<0.001\right)$.

\subsection{Change in the amount of food consumed}

A central question of this study was, if people consumed more food during the pandemic. Across the entire sample, $20.5 \%$, i.e. around a fifth of the respondents, stated that "more food" was consumed in their household (sum of the top values "much more" and "a little more") (Fig. 1).

When the increased consumption was analyzed for the different household segments, a high degree of heterogeneity in the population became obvious (Fig. 2). In households with no children and no income loss, the increase was lower compared to the average. In contrast, there was an increased caloric intake, especially in households with children and/or pandemic-related income losses.

Based on fisher's exact test for $2 \times 2$ tables (Table 5 ) it was checked if the mentioned differences between different household segments were significant. This holds for most $p$-values which supports the finding that income loss and kids in the household are drivers for an increased food consumption during the pandemic.

Table 4 Has anyone in your household been anxious about obtaining enough food to meet their requirements before and during Covid-19?

$\begin{array}{ll}\text { Before Covid-19 in \% } & \text { During } \\ & \begin{array}{l}\text { Covid-19 } \\ \text { in } \%\end{array}\end{array}$

\begin{tabular}{lrr}
\hline Frequently & 0.2 & 1.5 \\
Occasionally & 2.7 & 16.2 \\
Never & 97.1 & 82.2 \\
\hline
\end{tabular}




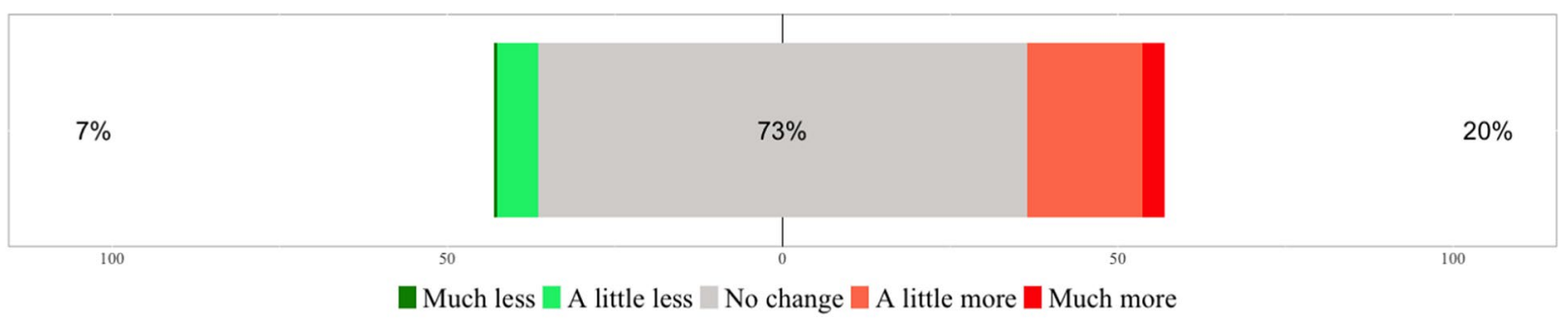

Fig. 1 Change in the amount of food consumed during Covid-19

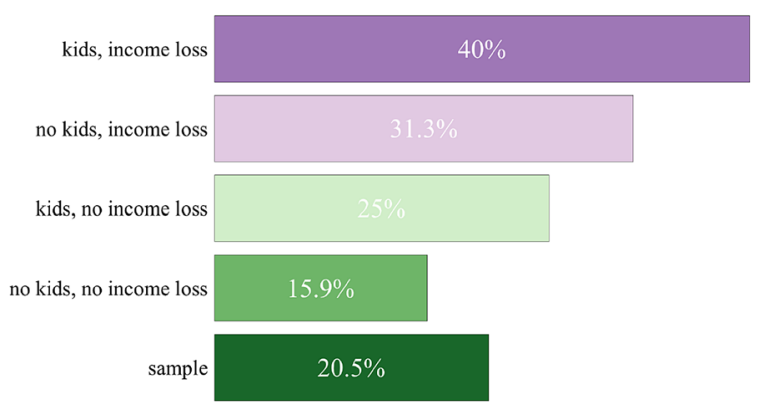

Fig. 2 Share of households with an increased consumption of food overall in different household segments (top scores "much more" and "a little more") consumption, there was not only a substitution but an additional consumption of the latter mentioned products.

For the different household segments (Table 6), again large group differences become apparent. E.g., $13.4 \%$ of the respondents declared a higher consumption of alcohol. However, this parameter increased only to $11.5 \%$ for households without children and without loss of income. In contrast, an increased alcohol consumption is found more frequently $(21.2 \%)$ in households with children and with reduced income.

For fruits and vegetables only $10.8 \%$ of the households with children and without income loss stated to consume less of these products. Compared to the time period before Covid-19, the consumption even increased during the pan-

Table 5 Fisher's exact test— $p$-values for groups differences between households segments concerning the increased food consumption

\begin{tabular}{llll}
\hline & $\begin{array}{l}\text { No kids, income loss vs. kids, income } \\
\text { loss }\end{array}$ & $\begin{array}{l}\text { No kids, income loss vs. kids, no } \\
\text { income loss }\end{array}$ & $\begin{array}{l}\text { No kids, income loss vs. } \\
\text { no kids, no income loss }\end{array}$ \\
\hline Less vs. no change & 0.81 & 0.01 & 0.02 \\
Less vs. more & 0.15 & 0.05 & 0.87 \\
No change vs. more & 0.06 & 0.43 & 0.00 \\
\hline & Kids, income loss vs. kids, no income & Kids, income loss vs. no kids, no & Kids, no income loss vs. \\
& loss & income loss & no kids, no income loss \\
\hline Less vs. no change & 0.08 & 0.27 & 0.28 \\
Less vs. more & 0.74 & 0.07 & 0.02 \\
No change vs. more & 0.01 & 0.00 & 0.01 \\
\hline
\end{tabular}

\subsection{Change in consumption frequency of various product categories}

During the corona lockdown, there were significant decreases in the frequency of consumption of fruits/vegetables, fish and meat (Fig. 3). In contrast, there were significant increases in the categories of canned goods, ready-made meals, cakes/cookies, sweets and alcohol. Thus, there was a tendency for fresh products to be partly substituted by more processed, and more durable (convenience) products or partially unhealthy foods (sweets, alcohol). In the context of the measured risen overall food demic. The opposite was true for households with children and a loss of income, (17.7\%). In this group, the consumption of fruits and vegetables was on average reduced during lockdown.

Contrarily to fruits and vegetables, only $16.6 \%$ of respondents from households with children and with no loss of income reported an increased consumption of ready-made meals. For households with children and a loss of income, a much higher value could be found (28.3\%). Similar results are shown for frozen food. In the product category meat, especially in households with children and a loss of income, meat consumption has declined (27.8\%). 

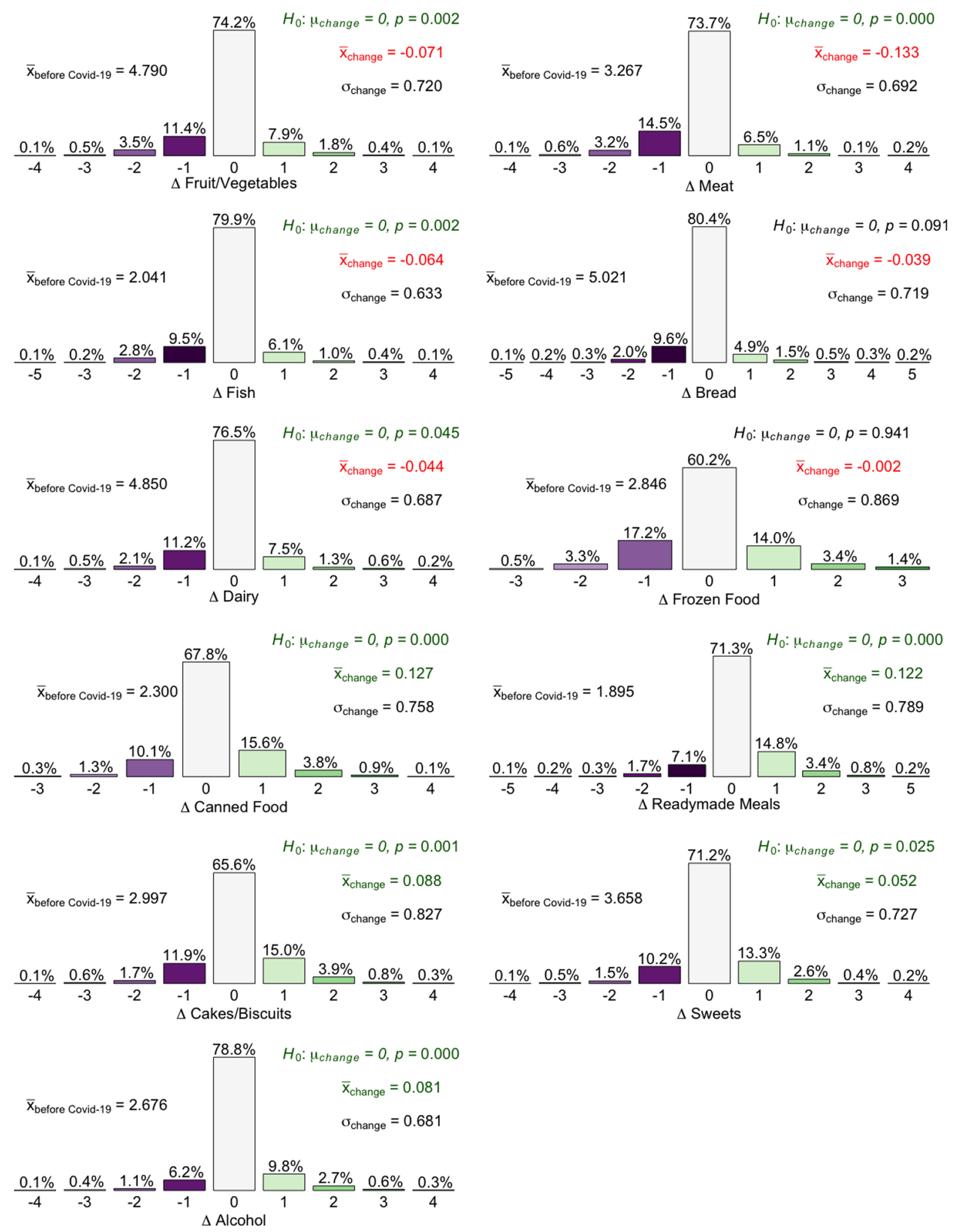

Fig. 3 Change in consumption frequency in certain product categories 
Table 6 Change in consumption frequency according to product groups and household segments (top scores- "much more" and "a little more" respectively "a little less" and "much less")

\begin{tabular}{llllll}
\hline & Sample (\%) & $\begin{array}{l}\text { No kids and no } \\
\text { income loss }(\%)\end{array}$ & $\begin{array}{l}\text { Kids and no } \\
\text { income loss } \\
(\%)\end{array}$ & $\begin{array}{l}\text { No kids and } \\
\text { income loss } \\
(\%)\end{array}$ & $\begin{array}{l}\text { Kids and } \\
\text { income loss } \\
(\%)\end{array}$ \\
\hline More alcohol & 13.4 & 11.5 & 13.6 & 17.1 & 21.2 \\
Less fruits/vegetables & 15.5 & 13.2 & 10.8 & 16.7 & 17.7 \\
More ready-meals & 19.2 & 16.6 & 15.7 & 23.6 & 28.3 \\
More tinned food & 20.4 & 18.4 & 22.8 & 24.8 & 24.7 \\
More frozen food & 18.8 & 16.7 & 16.4 & 20.8 & 26.0 \\
More sweets & 16.9 & 15.0 & 17.1 & 17.8 & 22.4 \\
Less meat & 18.4 & 16.7 & 17.8 & 20.8 & 27.8 \\
\hline
\end{tabular}

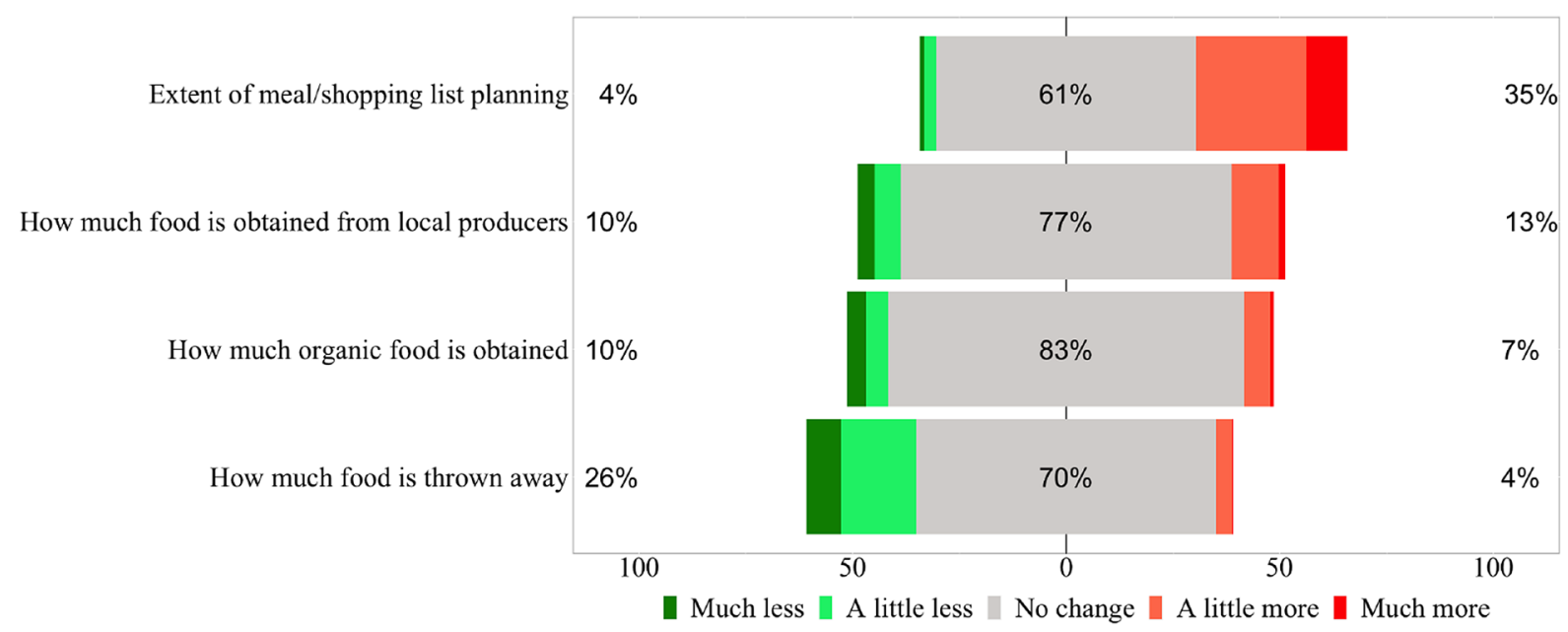

Fig. 4 Change in sustainable household behavior due to the corona pandemic

In households with children without loss of income, this value was only $17.8 \%$.

Based on fisher's exact test for $2 \times 2$ tables (Tables S8-14) it was checked if the mentioned differences between different household segments were significant. The analysis revealed that some but not the majority of the group differences were significant. But, it is to highlight that for two groups we had relatively small sample sizes. It is to expect that more of the analysed group differences are significant when a larger sample is considered.

\subsection{Price perception}

During the corona pandemic, there were price increases for meat and vegetables (Akter 2020). Agricultural economic research shows that for lower-income households the elasticity of the demand is in general stronger in comparison to other household segments (Thiele and Weiss 2003). That is plausible, because households with a lower income have to calculate more precisely to get along with their financial budget. Accordingly, the demand of higher-income households reacts less elastic. Based on this, it is to highlight that food prices during the corona pandemic were perceived very different across the segments. The majority $(63.9 \%)$ of households with children and income losses stated to spent more money on food compared to the pre-Covid-19 period. For households with children but no loss of income, this value was only $25.0 \%$.

\subsection{Changed eating habits in the context of the aspect of sustainability}

The study revealed only minor changes in consumer's behaviour concerning locally or organically produced food. There was no push towards locally or organically produced products as a result of the pandemic (Fig. 4). The changes in the positive as well as in the negative direction almost compensate each other.

In the context of sustainability, however, it can be shown that a relatively large group of $26 \%$ of the households threw away less food. In addition, more than a third planned meals and/or their grocery list more in advance. Based on a $\chi^{2}$ -square test, a significant relationship between the changed extent of planning and food waste avoidance could be 
Table 7 Change in sustainable household behaviour according to product groups and household segments (top scores- "much more" and "a little more" respectively "a little less" and "much less")

\begin{tabular}{lcllll}
\hline & Sample (\%) & $\begin{array}{l}\text { No kids and no } \\
\text { income loss (\%) }\end{array}$ & $\begin{array}{l}\text { Kids and no } \\
\text { income loss }(\%)\end{array}$ & $\begin{array}{l}\text { No kids and } \\
\text { income loss (\%) }\end{array}$ & $\begin{array}{l}\text { Kids and } \\
\text { income loss } \\
(\%)\end{array}$ \\
\hline More planning & 35.4 & 31.8 & 42.1 & 32.3 & 44.7 \\
More local & 12.5 & 11.9 & 17.1 & 10.7 & 12.9 \\
More organic & 7.0 & 6.9 & 6.4 & 7.1 & 8.2 \\
Less food waste & 25.8 & 24.2 & 30.0 & 29.6 & 22.4 \\
\hline
\end{tabular}

found. Households, which planned "a lot more" or "more" in advance indicated more often to threw away "a little less" or "much less" food during the pandemic $\left(\chi^{2}=139,77 ; d f\right.$ $=16 ; p<0.001$ ).

Across household segments, differences in the change of sustainable consumer behaviour could be found. In particular in households with kids, meals and shopping lists are planned more in advance (Table 7). Concerning local food, the highest rise can be found for households with kids but no income loss. Likewise this group indicated compared to all other segment most often $(30.0 \%)$ to produce less food waste during the pandemic. Interestingly, in households with kids but an income loss the lowest value for the reduction of food waste could be found $(22.4 \%)$.

\section{Conclusions}

This empirical study demonstrates that the corona lockdown has influenced eating habits of households. More food was eaten, and more convenience products such as ready meals and canned food with a longer shelf life were purchased. The consumption of alcohol and sweets has also increased. In return, the consumption of fresh fruits and vegetables declined.

These changes occurred to varying degrees in different household types. The overall increase in food consumption could be measured in particular for households with children and corona-related income losses. In households affected by budget restrictions, the factor "child" alone leads to a deterioration in the household diet. In other words, an increase in calorie intake that is well above average and a stronger switch towards an increased consumption of more unhealthy product groups. In this context, it is worrying that alcohol consumption has risen most strongly in precisely these households. Families who are financially affected by the pandemic represent a vulnerable group. With the ongoing pandemic, repeated lockdowns, corona-related closings of schools and kindergartens, severe health consequences are to expected long term, especially for this population group. The following measures can be taken by politicians and other stakeholders related to food production to counteract this negative development:
- Schools and kindergartens should be kept open. This could have a direct influence on the children's nutrition through meal planning. The application of the DGE quality standard ${ }^{7}$ for healthy and sustainable catering in community facilities for children should be made mandatory in this context.

- The quality of community catering for children must increase. Freshness, health and enjoyment should be in the foreground, and the caloric content of the menus adapted according to children's age. In addition, constant random quality controls by higher-level authorities are required.

- The municipalities and districts with the support of the state governments should not act according to the standard "good and above all cheap".

Due to the increase in the consumption of more processed food, the industry can also contribute to improve the health value of these (convenience) products by using more gentle and improved production methods and processes (e.g. high-pressure technology, pulsed electric fields). Government support can be provided from two sides in this context: By focussing on sustainable and healthy food in research funding to optimize the underlying procedures and processes or, if necessary, to develop them. Second, we propose to set the Nutri-Score as mandatory by law. The Nutri-Score is using a Nutrient Profiling System (NPS) to define five different categories of nutritional quality (from dark green associated with the letter A to dark orange with an E). The letter A represents a preferable score and $\mathrm{E}$ a detrimental score. Recent research demonstrates that the classification of foods according to the Nutri-Score is consistent with German Food-Based Dietary Guidelines. Food consumption as recommended by the guidelines is more favourably classified (e.g. most products composed mainly of fruits and vegetables were classified as A or B) than foods which consumption should be limited (e.g. nearly all of sugary snacks were classified as D or E) (Szabo de Edelenyi et al. 2019). Therefore, the Nutri-Score allows the consumer to differentiate between the offered options and to identify healthy

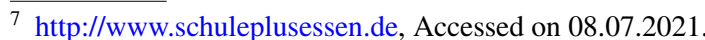


alternatives. This holds in particular for more processed convenience goods as ready-made meals. Dréano-Trécant et al. (2020) found for composite dishes a wide distribution concerning the Nutri-Score, which highlighted the large variability in prepared products in terms of nutritional quality, for which the Nutri-Score is a very useful tool to identify healthier options."

It is to highlight that a considerable part of the population feared not getting enough food during the lockdown. Therefore, we recommend that responsible state ministries run educational campaigns in non-pandemic times to encourage the population in stockpiling certain amount of foods on a mid- to long-term basis in order to avoid a run on grocery stores in times of crisis. Nonetheless, there is need for research to what extent this measure can prevent out-of-stock situations. Furthermore, it should be analysed to what extent the communication of political actors in the media has triggered the fear of not getting enough food.

Supplementary information The online version contains supplementary material available at https://doi.org/10.1007/s00003-021-01341-1.

Acknowledgements We thank the international Covid-19 research consortium (https://www.food-covid-19.org/) and in particular Jeremy Millard from the Danish Technology Institute (DTI) and Meike Janssen from Copenhagen Business School (CBS) for developing the idea and the development of a cross-country-study that set a focus on an important topic.

Funding Open Access funding enabled and organized by Projekt DEAL. This research received funding from LI-Food https://www. li-food.de.

Data availability statement The data presented in this study are available on request from the corresponding author. The data will be made publicly to a later stage.

\section{Declarations}

Conflict of interest The authors declare no conflict of interest.

Institutional review board statement Not applicable.

Informed consent statement Informed consent was obtained from all subjects involved in the study.

Open Access This article is licensed under a Creative Commons Attribution 4.0 International License, which permits use, sharing, adaptation, distribution and reproduction in any medium or format, as long as you give appropriate credit to the original author(s) and the source, provide a link to the Creative Commons licence, and indicate if changes were made. The images or other third party material in this article are included in the article's Creative Commons licence, unless indicated otherwise in a credit line to the material. If material is not included in the article's Creative Commons licence and your intended use is not permitted by statutory regulation or exceeds the permitted use, you will need to obtain permission directly from the copyright holder. To view a copy of this licence, visit http://creativecommons.org/licenses/by/4.0/.

\section{References}

Akter S (2020) The impact of COVID-19 related 'stay-at-home' restrictions on food prices in Europe: findings from a preliminary analysis. Food Secur 12(4):719-725

Antentas JM, Vivas E (2014) Impacto de la crisis en el derecho a una alimentación sana y saludable. Informe SESPAS 2014. Gaceta Sanitaria 28(S1):58-61

Bracale R, Vaccaro CM (2020) Changes in food choice following restrictive measures due to Covid-19. Nutr Metab Cardiovasc Dis 30(9):1423-1426

Cassady D, Jetter KM, Culp J (2007) Is price a barrier to eating more fruits and vegetables for low-income families? J Am Diet Assoc 107(11):1909-1915

Conway TL, Vickers RR, Ward HW, Rahe RH (1981) Occupational stress and variation in cigarette, coffee, and alcohol consumption. J Health Soc Behav 22(2):155-165

Dammeyer J (2020) An explorative study of the individual differences associated with consumer stockpiling during the early stages of the 2020 Coronavirus outbreak in Europe. Personal Individ Differ 167:110263

Dréano-Trécant L, Egnell M, Hercberg S, Galan P, Soudon J, Fialon M, Touvier M, Kesse-Guyot E, Julia C (2020) Performance of the front-of-pack nutrition label nutri-score to discriminate the nutritional quality of foods products: a comparative study across 8 European countries. Nutrients 12(5):1303

Hair J, Black W, Babin B, Anderson R (2010) Multivariate data analysis (Global ed.). Englewood Cliffs, Prentice Hall, NJ

Hendrickson D, Smith C, Eikenberry N (2006) Fruit and vegetable access in four low-income food deserts communities in Minnesota. Agric Hum Values 23(3):371-383

Laitinen J, Ek E, Sovio U (2002) Stress-related eating and drinking behavior and body mass index and predictors of this behavior. Prevent Med 34(1):29-39

Liu R, Zhang Y, Ge Y, Hu W, Sha B (2020) Precision regulation model of water and fertilizer for alfalfa based on agriculture cyber-physical system. IEEE Access 8:38501-38516

Monsivais P, Martin A, Suhrcke M, Forouhi NG, Wareham NJ (2015) Job-loss and weight gain in British adults: evidence from two longitudinal studies. Soc Sci Med 143:223-231

Monteiro CA (2009) Nutrition and health. The issue is not food, nor nutrients, so much as processing. Publ Health Nutr 12(5):729-731

Monteiro CA, Levy RB, Claro RM, De Castro IRR, Cannon G (2011) Increasing consumption of ultra-processed foods and likely impact on human health: evidence from Brazil. Public Health Nutr 14(1):5-13

Naumann E, Möhring K, Reifenscheid M, Wenz A, Rettig T, Lehrer R, Krieger U, Juhl S, Friedel S, Fikel M, Cornesse C, Blom AG (2020) COVID-19 policies in Germany and their social, political, and psychological consequences. Eur Policy Anal. https://doi.org/ 10.1002/epa2.1091

Rodríguez-Pérez C, Molina-Montes E, Verardo V, Artacho R, GarcíaVillanova B, Guerra-Hernández EJ, Ruíz-López MD (2020) Changes in dietary behaviours during the COVID-19 outbreak confinement in the Spanish COVIDiet study. Nutrients 12(6):1730

Scarmozzino F, Visioli F (2020) Covid-19 and the subsequent lockdown modified dietary habits of almost half the population in an Italian sample. Foods 9(5):675

Scarpa R, Rose JM (2008) Design efficiency for non-market valuation with choice modelling: how to measure it, what to report and why. Aust J Agric Resour Econ 52(3):253-282

Spitzer M (2020) Die Geschichte von 2 Pandemien. Ed Nervenheilkd 39:698-703

Swinburn BA, Kraak VI, Allender S, Atkins VJ, Baker PI, Bogard JR, Brinsden H, Calvillo A, De Schutter O, Devarajan R, Ezzati M, 
Friel S, Goenka S, Hammond RA, Hastings G, Hawkes C, Herrero M, Hovmand PS, Howden M, Jaacks LM, Kapetanaki AB, Kasman M, Kuhnlein HV, Kumanyika SK, Larijani B, Lobstein T, Long MW, Matsudo VK, Mills SD, Morgan G, Morshed A, Nece PM, Pan A, Patterson DW, Sacks G, Shekar M, Simmons GL, Smit W, Tootee A, Vandevijvere S, Waterlander WE, Wolfenden L, Dietz WH (2019) The global syndemic of obesity, undernutrition, and climate change: the lancet commission report. Lancet 393(10173):791-846

Szabo de Edelenyi F, Egnell M, Galan P, Druesne-Pecollo N, Hercberg S, Julia C (2019) Ability of the nutri-score front-of-pack nutrition label to discriminate the nutritional quality of foods in the German food market and consistency with nutritional recommendations. Arch Public Health 77(1):28

Thiele S, Weiss C (2003) Consumer demand for food diversity: evidence for Germany. Food Policy 28(2):99-115
Van Hal G (2015) The true cost of the economic crisis on psychological well-being: a review. Psychol Res Behav Manage 8:17-25

Vlontzos G, Duquenne M (2013) Identification of decision making for food under economic crisis: the case of Greece. Procedia Technol $8: 306-314$

Wen CP, Wu X (2012) Stressing harms of physical inactivity to promote exercise. Lancet 380(9838):192-193

Publisher's Note Springer Nature remains neutral with regard to jurisdictional claims in published maps and institutional affiliations. 